\title{
Intermittent high glucose exacerbates the aberrant production of adiponectin and resistin through mitochondrial superoxide overproduction in adipocytes
}

\author{
Jiazhong Sun, Yancheng Xu, Haohua Deng, Suxin Sun, Zhe Dai and Yanlei Sun \\ Department of Endocrinology, Zhongnan Hospital, Wuhan University, Wuhan 430071, People's Republic of China \\ (Correspondence should be addressed to J Sun; Email: sjz300@163.com)
}

\begin{abstract}
Hypoadiponectinemia and hyperresistinemia may be important in mediating signals from adipocytes to insulin-sensitive tissue and vasculature. However, the mechanism that mediates the aberrant production of adipokines remains poorly understood. In this study, we have investigated the effect of intermittent high glucose on the expression of adiponectin and resistin, and the production of 8-hydroxydeoxyguanosine (8-OHdG) and nitrotyrosine in the adipocytes, either in the presence or in the absence of $\mathrm{Mn}$ (III) tetrakis(4-benzoic acid) porphyrin chloride (MnTBAP) or thenoyltrifluoroacetone (TTFA). 3T3-L1 adipocytes were incubated for $72 \mathrm{~h}$ in media containing different glucose concentrations: $5 \mathrm{mmol} / \mathrm{l}$, $20 \mathrm{mmol} / \mathrm{l}, 5 \mathrm{mmol} / \mathrm{l}$ alternating with $20 \mathrm{mmol} / \mathrm{l}$ glucose, with or without MnTBAP and TTFA. We measured the expression of resistin and adiponectin. The production of nitrotyrosine and 8-OHdG as oxidative stress parameter was measured. Both constant and intermittent high glucose significantly suppressed the expression and secretion of adiponectin, and increased expression and secretion of resistin in mature adipocytes compared to normal glucose conditions. However, these effects were significantly greater under intermittent high glucose conditions compared to constant high glucose. The levels of nitrotyrosine and $8-\mathrm{OHdG}$ were significantly elevated under both intermittent and constant high glucose conditions, the effect being greater under intermittent high glucose. In addition, the antioxidants MnTBAP or TTFA reversed the aberrant production of adiponectin and resistin, as well as overproduction of nitrotyrosine and 8-OHdG in adipocytes induced by constant or intermittent high glucose. Intermittent high glucose exacerbates the aberrant production of adiponectin and resistin through reactive oxygen species overproduction at the mitochondrial transport chain level in adipocytes, indicating that glycemic variability has important pathological effects on the secretion of adipokines.
\end{abstract}

Journal of Molecular Endocrinology (2010) 44, 179-185

\section{Introduction}

Adipose tissue is a major endocrine organ, which releases a wide range of protein signals and factors termed adipokines. A number of adipokines, including leptin, adiponectin, resistin, plasminogen activator inhibitor-1, are linked to inflammation and the inflammatory response. The adipokines appear to be involved in a wide range of physiological processes, including hemostasis, lipid metabolism, blood pressure regulation, insulin sensitivity, and angiogenesis (Fruhbeck et al. 2001, Trayhurn \& Wood 2004). The aberrant production of inflammatory adipokines is increasingly considered to be etiologically important in the development of diseases linked to obesity, particularly type 2 diabetes, cardiovascular diseases, and the metabolic syndrome (Hotamisligil 2003, Yudkin 2003). Thus, type 2 diabetes and atherosclerosis, as well as the other components of the metabolic syndrome, have been causally linked to inflammation.

Aberrant production of adipose-derived adipokines, especially hypoadiponectinemia and elevated resistin levels, is now believed to play a causative role in the development of obesity-associated insulin resistance and cardiovascular disorders (Trayhurn \& Wood 2004, Lam \& Xu 2005). Various proinflammatory cytokines, such as tumor necrosis factor- $\alpha$ and interleukin- 6 , and reactive oxygen species (ROS) have been shown to increase expression of adipokines in adipocytes (Lin et al. 2005). Oxidative stress, endoplasmic reticulum stress, and nuclear factor kappa B (NF- $\mathrm{B})$ activation pathways also operate in adipocytes (Van Gaal et al. 2006). Oxidative stress and inflammation in adipose tissue can be exacerbated by hyperglycemia (Lin et al. 2005).

The increased production of superoxide by the mitochondrial electron transport chain plays a causative role in hyperglycemic damage (Nishikawa et al. 2000). A possible involvement of this pathway in the hyperglycemia-induced aberrant production of inflammatory adipokines from adipocytes has not yet been reported. Therefore, the purpose of this study was to verify a possible connection between mitochondrial ROS production and aberrant production of adiponectin and resistin induced by both intermittent and 
constant high glucose. To this aim, 3T3-L1 adipocytes culture medium was enriched with the superoxide dismutase (SOD) mimetic Mn(III) tetrakis(4-benzoic acid) porphyrin chloride (MnTBAP; Quagliaro et al. 2003), a cell-permeable superoxide dismutase mimetic or thenoyltrifluoroacetone (TTFA), an inhibitor of mitochondrial complex II (Nishikawa et al. 2000). Nitrotyrosine and 8-hydroxy-deoxyguanosine (8-OHdG) have been measured as an index of oxidative damage.

\section{Materials and methods}

\section{Cell culture}

3T3-L1 cells (Wuhan University Type Culture Collection) were cultured in high glucose DMEM supplemented with $10 \%$ FBS (Sigma Chemicals) and antibiotics. The differentiation of 3T3-L1 preadipocytes to mature adipocytes was performed using insulin, dexamethasone, and 3-isobutyl-l-methylxanthine as described previously (Lin et al. 2005). On the 10th day post-induction, a vast majority of cells $(\geq 90 \%)$ had accumulated into lipid droplets (data not shown). Then they were exposed to the experimental conditions for $72 \mathrm{~h}$. The cells were randomly divided into three groups: 1) continuous normal glucose medium $(5 \mathrm{mmol} / \mathrm{l})$, alternating $5 \mathrm{mmol} / 1$ glucose fresh media every $6 \mathrm{~h} ; 2$ ) continuous high glucose medium $(25 \mathrm{mmol} / \mathrm{l})$, alternating $25 \mathrm{mmol} / \mathrm{l}$ glucose fresh media every $6 \mathrm{~h} ; 3$ ) intermittent high glucose medium $(5 / 25 \mathrm{mmol} / \mathrm{l})$, alternating normal $(5 \mathrm{mmol} / \mathrm{l})$ and high glucose $(25 \mathrm{mmol} / \mathrm{l})$ media every $6 \mathrm{~h}$; and $10 \mu \mathrm{mmol} / \mathrm{l}$ TTFA and $100 \mu \mathrm{mmol} / 1 \mathrm{MnTBAP}$, were also added individually to the three media previously described.

\section{Determination of 8-OHdG}

8-OHdG amount was determined in 3T3-L1 adipocytes DNA digests using Bioxytech 8-OHdG-EIA Kit, a competitive ELISA. Adipocytes DNA was isolated using DNAzol Reagent, according to the manufacturer's instructions, and quantified using a spectrophotometer. Samples containing $400 \mu \mathrm{g}$ of DNA were resuspended in $50 \mu \mathrm{l}$ reaction mixture, containing $100 \mathrm{mmol} / \mathrm{l}$ sodium acetate $(\mathrm{pH} 5 \cdot 0)$ and $5 \mathrm{mmol} / \mathrm{l} \mathrm{MgCl}_{2}$, and digested with $1 \mu \mathrm{l} \mathrm{DNaseI}$, for $10 \mathrm{~min}$ at room temperature. DNAdigested samples were added to the microtiter plate precoated with $8-\mathrm{OHdG}$, and the assay was performed according to the manufacturer's instructions.

\section{Determination of nitrotyrosine}

Nitrotyrosine content was evaluated by ELISA. Briefly, an identical amount of protein from cell lysates $(50 \mu \mathrm{g})$ was applied to a Maxisorp ELISA plate (NUNC Brand
Products) together with nitrated BSA standard and allowed to bind overnight at $4^{\circ} \mathrm{C}$. After blocking, wells were incubated at $37^{\circ} \mathrm{C}$ for $1 \mathrm{~h}$ with a mouse monoclonal antibody anti-nitrotyrosine (Upstate Biotechnology, Lake Placid, NY, USA; $5 \mu \mathrm{g} / \mathrm{ml}$ ) and then for $45 \mathrm{~min}$ at $37^{\circ} \mathrm{C}$ with a peroxidase conjugated goat anti-mouse IgG secondary antibody diluted 1:1000. After washing, peroxidase reaction product was generated using $3,3^{\prime}, 5,5^{\prime}$-tetramethylbenzidine (TMB) peroxidase substrate.

\section{Adiponectin and resistin quantification}

The conditioned culture medium from 3T3-L1 adipocytes was collected at different time points as indicated, and the concentrations of adiponectin and resistin in the conditioned medium were measured using the mouse adiponectin and resistin assay kits from Linco Research Inc. (St Charles, MO, USA). The assay was performed using the sandwich ELISA according to the manufacturers' protocols.

\section{Analysis of adiponectin and resistin gene expression}

Total RNA was isolated from cultured 3T3-L1 cells using the TRIZOL method (Invitrogen) and reverse transcribed using the reverse transcription system. In brief, the reverse transcription mixture contained $1 \mathrm{mg}$ total RNA, $0.5 \mathrm{mg}$ oligod (T) primer, $4 \mathrm{ml} 5 \times \mathrm{RT}$ buffer, $0.5 \mathrm{mmol} / \mathrm{l}$ deoxynucleotides, $50 \mathrm{U}$ of RNase inhibitor, and $200 \mathrm{U}$ reverse transcriptase (Promega) in a total volume of $20 \mu \mathrm{l}$. The reaction mixture underwent PCR carried out at $42{ }^{\circ} \mathrm{C}$ for $1 \mathrm{~h}$ followed by heat inactivation at $95{ }^{\circ} \mathrm{C}$ for $5 \mathrm{~min}$. The number of cycles and reaction temperatures used in the PCR assay were optimized to provide a linear relationship between the amount of input template and the amount of PCR product. The amount of PCR products formed in each cycle was evaluated on the basis of SYBR Green I fluorescence. All amplification reactions were performed using the Mx3000 Multiplex Quantitative PCR System. Results were analyzed with Stratagene Mx3000 software. The primers used for amplification, together with their specific optimum cycling conditions, were as follows: mouse adiponectin (a $219 \mathrm{bp}$ product): sense primer 5'-AAGGACAAGGCCGTTCTCT-3'; antisense primer 5'-TATGGGTAGTTGCAGTCAGTTGG-3'; annealing temperature $61{ }^{\circ} \mathrm{C} ; 35$ cycles. Mouse resistin (a $175 \mathrm{bp}$ product): sense primer $5^{\prime}$-GTACCCACGGGATGAAGAACC-3'; antisense primer 5'-CAAGGTTGGATGGGGGCGAAGGG-3' $3^{\prime}$; annealing temperature $60^{\circ} \mathrm{C}$; 33 cycles. $\beta$-actin (a $489 \mathrm{bp}$ product) sense primer 5'-CCAGGGTGTGATGGTGGAATG-3'; antisense primer 5'-CGCACGATTTCCCTCTCAGCTG-3'; annealing temperature $59{ }^{\circ} \mathrm{C} ; 33$ cycles. 

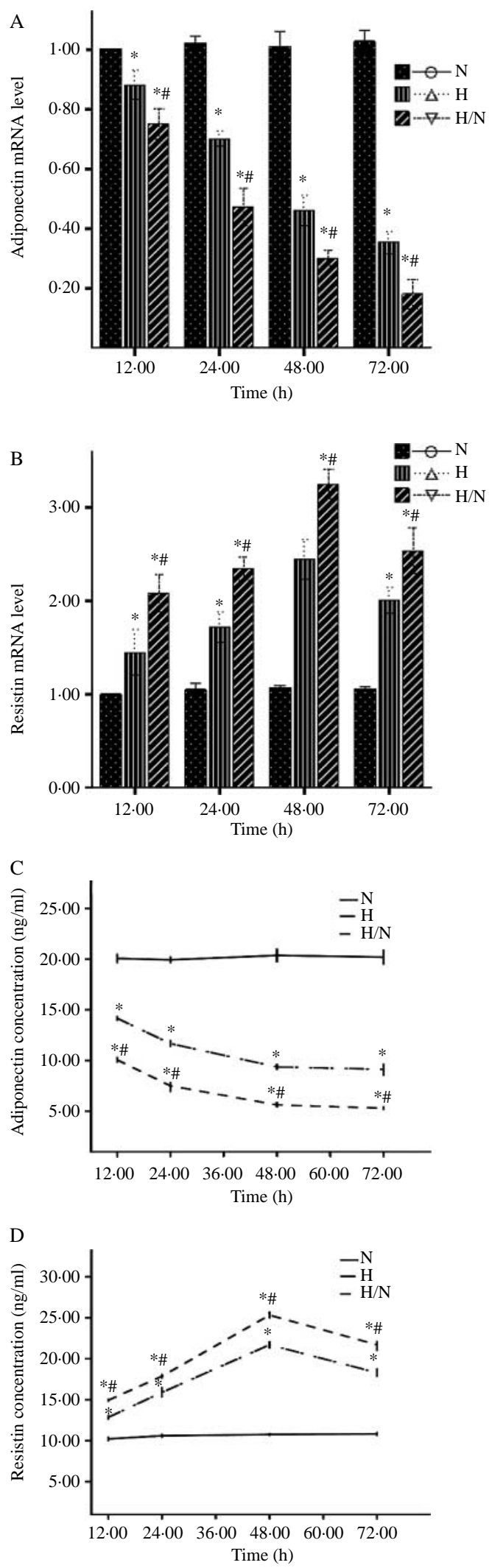

\section{Statistical analysis}

All experimental conditions were replicated fivefold. Results are expressed as mean \pm s.D. The inter-group comparisons were made by Student's $t$-test or one-way ANOVA. Analyses were performed by the software package, SPSS 13.0 (SPSS, Chicago, IL, USA). A value of $P<0.05$ was considered significant.

\section{Results}

\section{Intermittent high glucose markedly decreases adiponectin production in adipocytes}

To examine the effects of high glucose on the expression of adiponectin, fully differentiated 3T3-L1 adipocytes were cultured in the constant or intermittent high glucose condition for different time periods. Quantitative real-time PCR demonstrated that constant and intermittent high glucose significantly decreased the steady-state mRNA abundance of the adiponectin gene in a timedependent manner. A modest reduction was observed at $12 \mathrm{~h}$, and further deteriorated afterwards (Fig. 1A).

Quantitative ELISA analysis showed that the adiponectin concentrations in the conditioned media were suppressed by 16 and $43 \%$ at $12 \mathrm{~h}$ after constant and intermittent high glucose treatment (Fig. 1C), and reached the maximum suppression at $48 \mathrm{~h}$. The expression of adiponectin showed a great decrease in constant high glucose condition in comparison with normal glucose condition, and this decrease was even more marked in intermittent glucose condition. This result suggests that constant and intermittent high glucose treatment not only decreases the mRNA level of the adiponectin gene, but also inhibits its protein synthesis and secretion from adipocytes, but in the latter condition the decrease was more marked.

MnTBAP and TTFA can prevent the hyperglycemiainduced reduction in the adiponectin concentrations. The content of adiponectin in cell culture supernatants of constant and oscillating high glucose conditions after $48 \mathrm{~h}$ became comparable to the content in normal glucose conditions (Fig. 2A).

Figure 1 Time-dependent effects of intermittent and constant high glucose on the gene expression and protein production of adiponectin and resistin in 3T3-L1 adipocytes. N, constant normal glucose $(5 \mathrm{mmol} / \mathrm{l}) ; \mathrm{H}$, constant high glucose $(25 \mathrm{mmol} / \mathrm{l}) ; \mathrm{H} / \mathrm{N}$, $5 \mathrm{mmol} / \mathrm{l}$ alternating with $25 \mathrm{mmol} / \mathrm{l}$ glucose. Fully differentiated 3T3-L1 adipocytes were cultured in intermittent or constant high glucose condition for $12,24,48$, and $72 \mathrm{~h}$. Total RNA purified from these samples was subjected to quantitative PCR analysis to determine the mRNA levels of adiponectin (A) and resistin (B). The protein concentrations of adiponectin (C) and resistin (D) in the conditioned medium were quantified as described in Materials and methods. For comparison, the levels of the adiponectin and resistin mRNA from 12-h time point in $5 \mathrm{mmol} / \mathrm{l}$ glucose condition were arbitrarily set at $1 .{ }^{\star} P<0.01$ vs $5 \mathrm{mmol} / \mathrm{l}$ glucose, ${ }^{\#} P<0.01$ versus constant high glucose $(n=5-8)$. 


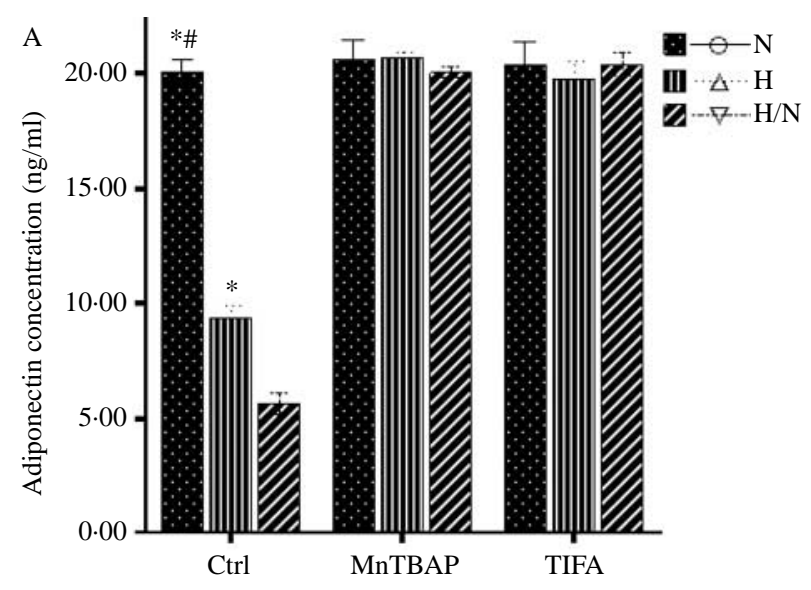

but also inhibits its protein synthesis and secretion from adipocytes.

MnTBAP and TTFA produced an equally marked reduction in protein concentration of the resistin gene obtained in cells, cultured in constant high glucose and intermittent high glucose in comparison with the same conditions without the addition of the inhibitor (Fig. 2B).

\section{Nitrotyrosine and 8-OHdG measurement}

After $48 \mathrm{~h}$, when no oxidative stress inhibitory substance was added, the concentration of nitrotyrosine in cell protein extract revealed an increase in the constant
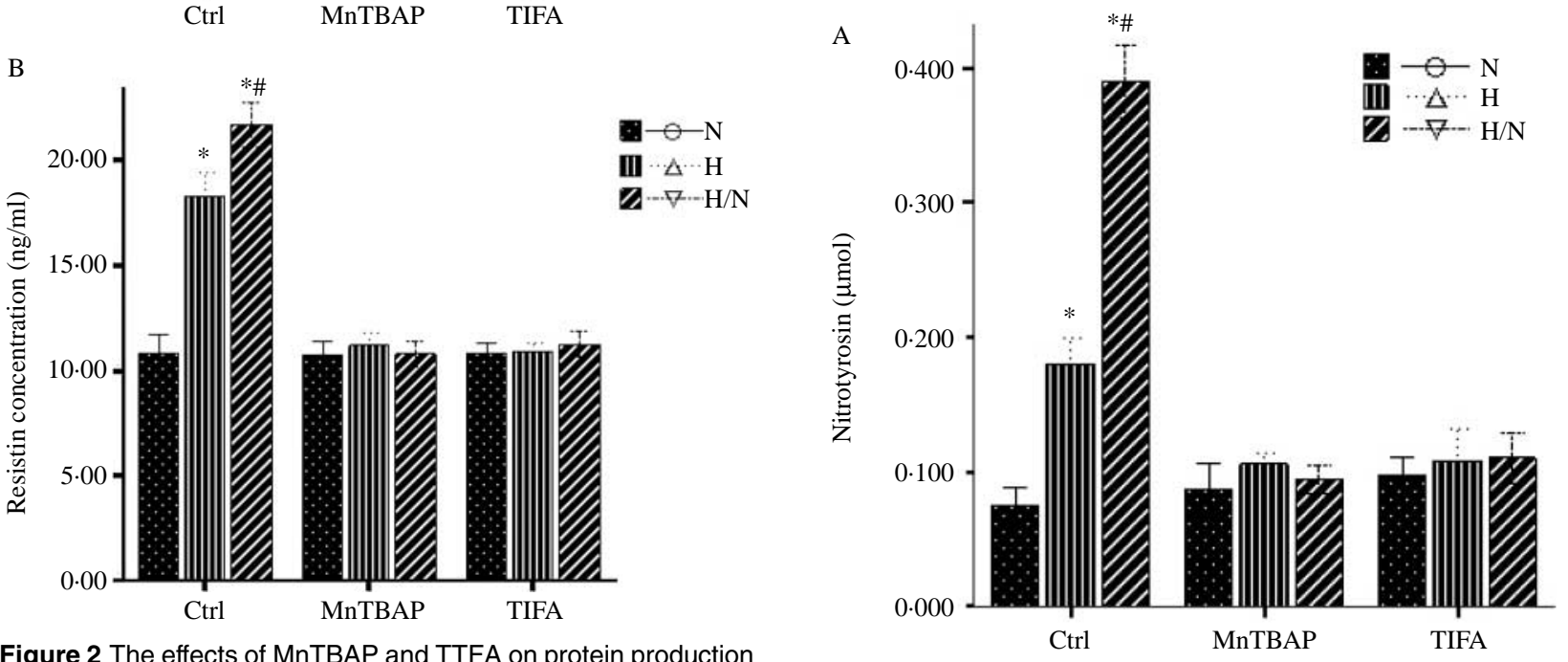

Figure 2 The effects of MnTBAP and TTFA on protein production of adiponectin (A) and resistin (B) in 3T3-L1 adipocytes cultured in intermittent or constant high glucose condition for $48 \mathrm{~h}$.

$\mathrm{N}$, constant normal glucose $(5 \mathrm{mmol} / \mathrm{l}) ; \mathrm{H}$, constant high glucose (25 mmol/l); H/N, $5 \mathrm{mmol} / \mathrm{l}$ alternating with $25 \mathrm{mmol} / \mathrm{l}$ glucose. ${ }^{*} P<0.01$ vs $5 \mathrm{mmol} / \mathrm{l}$ glucose, ${ }^{\#} P<0.05$ versus constant high glucose $(n=5-8)$.

\section{Intermittent high glucose markedly increases resistin expression in adipocytes}

In contrast to adiponectin, both the steady-state mRNA abundance of the resistin gene and its protein concentration in the conditioned medium were markedly elevated in both constant and intermittent high glucose in a time-dependent manner, but in the latter condition the increase was more marked (Fig. 1B and D). The significant increase in mRNA abundance of resistin was observed at $12 \mathrm{~h}$ after constant and intermittent high glucose treatment, further deteriorated afterwards and reached the maximum expression at $48 \mathrm{~h}$. Resistin protein concentration was elevated at $12 \mathrm{~h}$ and reached the maximum expression at $48 \mathrm{~h}$. This result suggests that constant and intermittent high glucose treatment not only increases the mRNA level of the adiponectin gene,

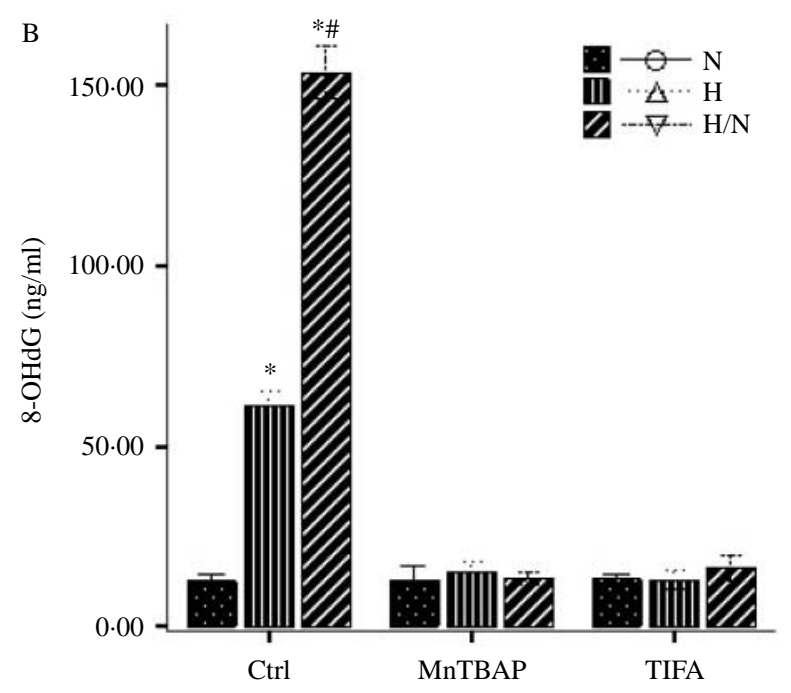

Figure 3 The effects of MnTBAP and TTFA on production of nitrotyrosine $(A)$ and 8-OHdG (B) in 3T3-L1 adipocytes cultured in intermittent or constant high glucose condition for $48 \mathrm{~h}$. N, constant normal glucose $(5 \mathrm{mmol} / \mathrm{l}) ; \mathrm{H}$, constant high glucose $(25 \mathrm{mmol} / \mathrm{l})$; $\mathrm{H} / \mathrm{N}, 5 \mathrm{mmol} / \mathrm{l}$ alternating with $25 \mathrm{mmol} / \mathrm{l}$ glucose. ${ }^{*} P<0.01 \mathrm{vs}$ $5 \mathrm{mmol} / \mathrm{l}$ glucose, ${ }^{\#} P<0.05$ versus constant high glucose $(n=5-8)$. 
high glucose condition and more in intermittent high glucose condition in comparison with the normal glucose condition. The adding of the inhibitory substances, MnTBAP and TTFA, equally inhibited the increase of nitrotyrosine in the constant and intermittent high glucose condition as regards the same conditions where no inhibitor was added (Fig. 3A).

Similarly, after 48 -h culture, the amount of $8-\mathrm{OHdG}$ increased both in the constant and in the intermittent high glucose condition, but in the latter the content was more than doubled (Fig. 3). The presence of the inhibitors (MnTBAP and TTFA) equally blocked the 8-OHdG production in both the constant and intermittent high glucose conditions (Fig. 3B).

\section{Discussion}

In the present studies, we have demonstrated that both the constant and intermittent high glucose markedly suppressed adiponectin mRNA expression and its protein secretion, and increased resistin production in mature adipocytes.

3T3-L1 adipocytes are a widely used cell culture model of white adipocytes (Rosen \& Spiegelman 2000). In mice, resistin is highly and specifically expressed in white adipose tissue (Steppan et al. 2001a). Overall, human resistin is only $53 \%$ identical with its murine counterpart, but identity is highest in the C-terminal signature sequence region (Steppan et al. 2001b). Surprisingly, unlike murine resistin, the expression level of resistin mRNA in human adipose tissue is extremely low but detectable by real-time PCR and is about $1 / 250$ of that in the mouse. Remarkably, resistin mRNA is abundant in mononuclear blood cells (Savage et al. 2001). Resistin is highly expressed in preadipocytes isolated from plastic surgery patients, and resistin expression decreased during adipogenesis, contrary to the results in mice (Janke et al. 2002). Plasma resistin concentration is reported to be in the range of $3-13 \mathrm{ng} / \mathrm{ml}$ in healthy subjects with levels approaching $40 \mathrm{ng} / \mathrm{ml}$ in obese individuals (Pfutzner et al. 2003). McTernan et al. (2002) detected 4·2-fold higher resistin expression and protein than in peripheral fat depots in thigh and breast in human. Resistin mediates insulin resistance, but this role may be limited to rodents. In humans, data on the role of this adipocytokine in insulin sensitivity and obesity are controversial. Some authors indicated that increased serum resistin levels are associated with increased obesity, visceral fat (Pagano et al. 2005), and type 2 diabetes (Burnett $e t$ al. 2006), while other groups failed to observe such correlations (Zou et al. 2005). Verma et al. (2003) demonstrated that resistin activates vascular endothelium, causing release of endothelin-1.
Additionally, resistin treatment increased endothelial cell expression of VCAM-1 and MCP-1. Thus, resistin exerts proinflammatory changes in vascular endothelium in experimental settings. As a result, resistin has become an inflammatory marker of atherosclerotic disease (Reilly et al. 2005). Hence, resistin may play a prominent role in the pathogenesis of diabetes-related vascular disease. Adiponectin is a protein hormone secreted almost exclusively by adipocytes from mice and human, which exhibits antiatherogenic and insulinsensitizing properties (Kadowaki \& Yamauchi 2005). Lower adiponectin concentrations were found in patients with obesity and diabetes (Cavusoglu et al. 2006, Fantuzzi \& Mazzone 2007), and the treatment of apolipoprotein E-deficient mice with an adiponectinexpressing adenovirus has proven to reduce atherosclerotic plaque formation (Fantuzzi \& Mazzone 2007). Hypoadiponectinemia are an independent predictor of all-cause mortality, cardiac mortality, and myocardial infarction in patients presenting with chest pain (Kadowaki \& Yamauchi 2005).

In this study, we found that intermittent high glucose induces a greater aberrant production of adiponectin and resistin than constant high glucose. These findings suggest that intermittent high glucose could be more deleterious to the dysregulation of adipokines from adipocytes than constant high glucose, supporting a pathophysiologic link between intermittent high glucose and increased cardiovascular risk (Ceriello et al. 2008). Intermittent high glucose may be more dangerous for the cells than constant high glucose. Mesangial cells cultured in periodic high glucose concentration increase matrix production more than the cells cultured in high stable glucose (Takeuchi et al. 1995). Similarly, fluctuations of glucose display a more dangerous effect than stable high glucose on both tubulointerstitial cells and human renal cortical fibroblasts, in terms of collagen synthesis and cell growth (Jones et al. 1999). New diabetes therapies focused on reducing postprandial hyperglycemia have become available and may benefit glycemic control and cardiovascular disease risk factor levels (Bastyr et al. 2000). It is now recognized that both hyperglycemia at $2 \mathrm{~h}$ during an oral glucose challenge and glucose fluctuation (Ceriello 2004) are strong predictors of cardiovascular disease and microangiophatic complications (Singleton et al. 2003), and it has been suggested that these 'hyperglycemic spikes' may play a direct and significant role in the pathogenesis of diabetic vascular complications (Ceriello 1998).

The present study also addresses the signaling pathways responsible for dysregulation of adipokines induced by high glucose treatment in adipocytes. We found that constant high glucose produced an increase in oxidative stress generation. Moreover, the pathway involved in the damaging effect of intermittent high 
glucose on adipocytes is, at least in part, the same one working in stable high glucose concentrations. It appears noteworthy that it is enhanced in intermittent high glucose conditions. We confirm that intermittent glucose enhances oxidative stress generation and worsens the effects of high glucose on dysfunction of adipocytes. Dysregulation of adiponectin and resistin expression is accompanied by an increase of both nitrotyrosine and 8-OHdG, and is reversed by the SOD mimetic MnTBAP. This study showed that inhibiting the mitochondrial electron transport complex II preserves adipocytes from dysregulation of adipokines expression induced by high glucose treatment, both constant and intermittent. The effect of TTFA, a specific antioxidant active at mitochondrial level, in normalizing dysregulation of adipokines expression, as well as nitrotyrosine and $8-\mathrm{OHdG}$, was equivalent to those of MnTBAP, suggesting that an overproduction of free radicals at mitochondrial level is the mediator of the dysfunction of adipocytes. Actually, MnTBAP and SOD were active against ROS originating in different districts inside the cell. The fact that a specific mitochondrial oxidative stress inhibitor achieves the same results suggests that the major source of ROS inside the cell, due to high glucose exposition, is the mitochondrial electron transport chain. To be specific, TTFA selectively inhibits mitochondrial complex II activity; inhibition of entrance of electron to ubiquinone from complex II blocks off ROS generation, preventing all downstream processes.

At present, the molecular mechanisms specifically triggered on cultured adipocytes by periodically changing glucose concentrations are not known. A possible explanation may be that during chronic exposure to high glucose, some metabolic variations induced by this constant situation might change or feedback regulatory cell controls, partially counteracting the glucose toxic effect. Intermittent exposure to high glucose might reduce such adaptation, causing more pronounced toxicity.

In conclusion, our study shows that the exposure of adipocytes to intermittent high glucose produces the dysregulation of several adipokines, and supports the hypothesis that glucose fluctuation may be involved in the aberrant secretion of adipokines. Moreover, our data suggest that this phenomenon is related to overproduction of mitochondrial superoxide in adipocytes.

\section{Declaration of interest}

The authors declare that there is no conflict of interest that could be perceived as prejudicing the impartiality of the research reported.

\section{Funding}

This study was funded by Hubei Provincial Bureau of Health Science Foundation for Young Scholars (grants QJX2008-29).

\section{References}

Bastyr EJ, Stuart CA, Brodows RG, Schwartz S, Graf CJ, Zagar A \& Robertson KE 2000 Therapy focused on lowering postprandial glucose, not fasting glucose, may be superior for lowering HbAlc: IOEZ Study Group. Diabetes Care 23 1236-1241.

Burnett MS, Devaney JM, Adenika RJ, Lindsay R \& Howard BV 2006 Crosssectional associations of resistin, coronary heart disease and insulin resistance. Journal of Clinical Endocrinology and Metabolism 91 64-68.

Cavusoglu E, Ruwende C, Chopra V, Yanamadala S, Eng C, Clark LT, Pinsky DJ \& Marmur JD 2006 Adiponectin is an independent predictor of allcause mortality, cardiac mortality, and myocardial infarction in patients presenting with chest pain. European Heart Journal 27 2300-2309.

Ceriello A 1998 The emerging role of post-prandial hyperglycaemic spikes in the pathogenesis of diabetic complications. Diabetic Medicine 15 188-193.

Ceriello A 2004 Impaired glucose tolerance and cardiovascular disease: the possible role of post-prandial hyperglycemia. American Heart Journal 147 803-807.

Ceriello A, Esposito K, Piconi L \& Ihnat MA 2008 Oscillating glucose is more deleterious to endothelial function and oxidative stress than mean glucose in normal and type 2 diabetic patients. Diabetes $\mathbf{5 7}$ 1349-1354.

Fantuzzi G \& Mazzone T 2007 Adipose tissue and atherosclerosisexploring the connection. Arteriosclerosis, Thrombosis, and Vascular Biology 27 996-1003.

Fruhbeck C, Gomez-Ambrosi J, Muruzabal FJ \& Burrell MA 2001 The adipocyte: a model for integration of endocrine and metabolic signaling in energy metabolism regulation. American Journal of Physiology. Endocrinology and Metabolism 280 E827-E847.

Hotamisligil GS 2003 Inflammatory pathways and insulin action. International Journal of Obesity 27 S53-S55.

Janke J, Engeli S, Gorzelniak K, Luft FC \& Sharma AM 2002 Resistin gene expression in human adipocytes is not related to insulin resistance. Obesity Research 10 1-5.

Jones SC, Saunders HJ \& Qi W 1999 Intermittent high glucose enhances cell growth and collagen synthesis in cultured human tubulointerstitial cells. Diabetologia 42 1113-1119.

Kadowaki T \& Yamauchi T 2005 Adiponectin and adiponectin receptors. Endocrine Reviews 26 439-451.

Lam KS \& Xu A 2005 Adiponectin: protection of the endothelium. Current Diabetes Reports 5 254-259.

Lin Y, Berg AH \& Iyengar P 2005 The hyperglycemia-induced inflammatory response in adipocytes: the role of reactive oxygen species. Journal of Biological Chemistry 280 4617-4626.

McTernan PG, McTernan CL, Chetty R, Jenner K, Fisher FM, Lauer MN, Crocker J, Barnett AH \& Kumar S 2002 Increased resistin gene and protein expression in human abdominal adipose tissue. Journal of Clinical Endocrinology and Metabolism 872407.

Nishikawa T, Edelstein D \& Du XL 2000 Normalizing mitochondrial superoxide production blocks three pathways of hyperglycaemic damage. Nature 404 787-790.

Pagano C, Marin O, Calcagno A, Schiappelli P, Pilon C \& Milan G 2005 Increased serum resistin in adults with Prader Willi syndrome is related to obesity and not to insulin resistance. Journal of Clinical Endocrinology and Metabolism 90 4335-4340.

Pfutzner A, Langenfeld M, Kunt T, Lobig M \& Forst T 2003 Evaluation of human resistin assays with serum from patients with type 2 diabetes and different degrees of insulin resistance. Clinical Laboratory 49 571-576. 
Quagliaro L, Piconi L \& Assaloni R 2003 Intermittent high glucose enhances apoptosis related to oxidative stress in human umbilical vein endothelial cells: the role of protein kinase $\mathrm{C}$ and $\mathrm{NAD}(\mathrm{P}) \mathrm{H}-$ oxidase activation. Diabetes 52 2795-2804.

Reilly MP, Lehrke M, Wolfe ML, Rohatgi A, Lazar MA \& Rader DJ 2005 Resistin is an inflammatory marker of atherosclerosis in humans. Circulation 11 932-939.

Rosen ED \& Spiegelman BM 2000 Molecular regulation of adipogenesis. Annual Review of Cell and Developmental Biology 16 145-171.

Savage DB, Sewter CP, Klenk ES, Segal DG, Vidal-Puig A, Considine RV \& O'Rahilly S 2001 Resistin/Fizz3 expression in relation to obesity and peroxisome proliferator-activated receptor gamma action in humans. Diabetes 50 2199-2202.

Singleton JR, Smith AG, Russell JW \& Feldman EL 2003 Microvascular complications of impaired glucose tolerance. Diabetes 52 2867-2873.

Steppan CM, Bailey ST, Bhat S, Brown EJ, Banerjee RR, Wright CM,

Patel HR, Ahima RS \& Lazar MA 2001 $a$ The hormone resistin links obesity to diabetes. Nature 409 307-312.

Steppan CM, Brown EJ, Wright CM, Bhat S, Banerjee RR, Dai CY, Enders GH, Silberg DG, Wen X, Wu GD et al. 2001b A family of tissue-specific resistin-like molecules. PNAS 98 502-506.
Takeuchi A, Throckmorton DC \& Brogden AP 1995 Periodic high extracellular glucose enhances production of collagens III and IV by mesangial cells. American Journal of Physiology 268 F13-F19.

Trayhurn P \& Wood IS 2004 Dipokines: inflammation and the pleiotropic role of white adipose tissue. British Journal of Nutrition 92 347-355.

Van Gaal LF, Mertens IL \& De Block CE 2006 Mechanisms linking obesity with cardiovascular disease. Nature 444 875-880.

Verma S, Li SH, Wang CH, Fedak PW, Li RK, Weisel RD \& Mickle DA 2003 Resistin promotes endothelial cell activation: further evidence of adipokine-endothelial interaction. Circulation 108 736-740.

Yudkin JS 2003 Adipose tissue, insulin action and vascular disease: inflammatory signals. International Journal of Obesity 27 S25-S28.

Zou CC, Liang L, Hong F, Fu JF \& Zhao ZY 2005 Serum adiponectin, resistin levels and non alcoholic fatty liver disease in obese children. Endocrine Journal 52 519-524.

Received in final form 2 October 2009 Accepted 16 November 2009 